\title{
APSPS AERIAL PHOTOGRAPHY SUMMARY RECORD SYSTEM
}

31/ Wyoming

DECEMBER 1980

NATIONAL CARTOGRAPHIC INFORMATION CENTER NATIONAL MAPPING DIVISION

U.S. DEPARTMENT OF THE INTERIOR-GEOLOGICAL SURVEY 


\section{APSRS STATE-BASE GRAPHIC INDEXES}

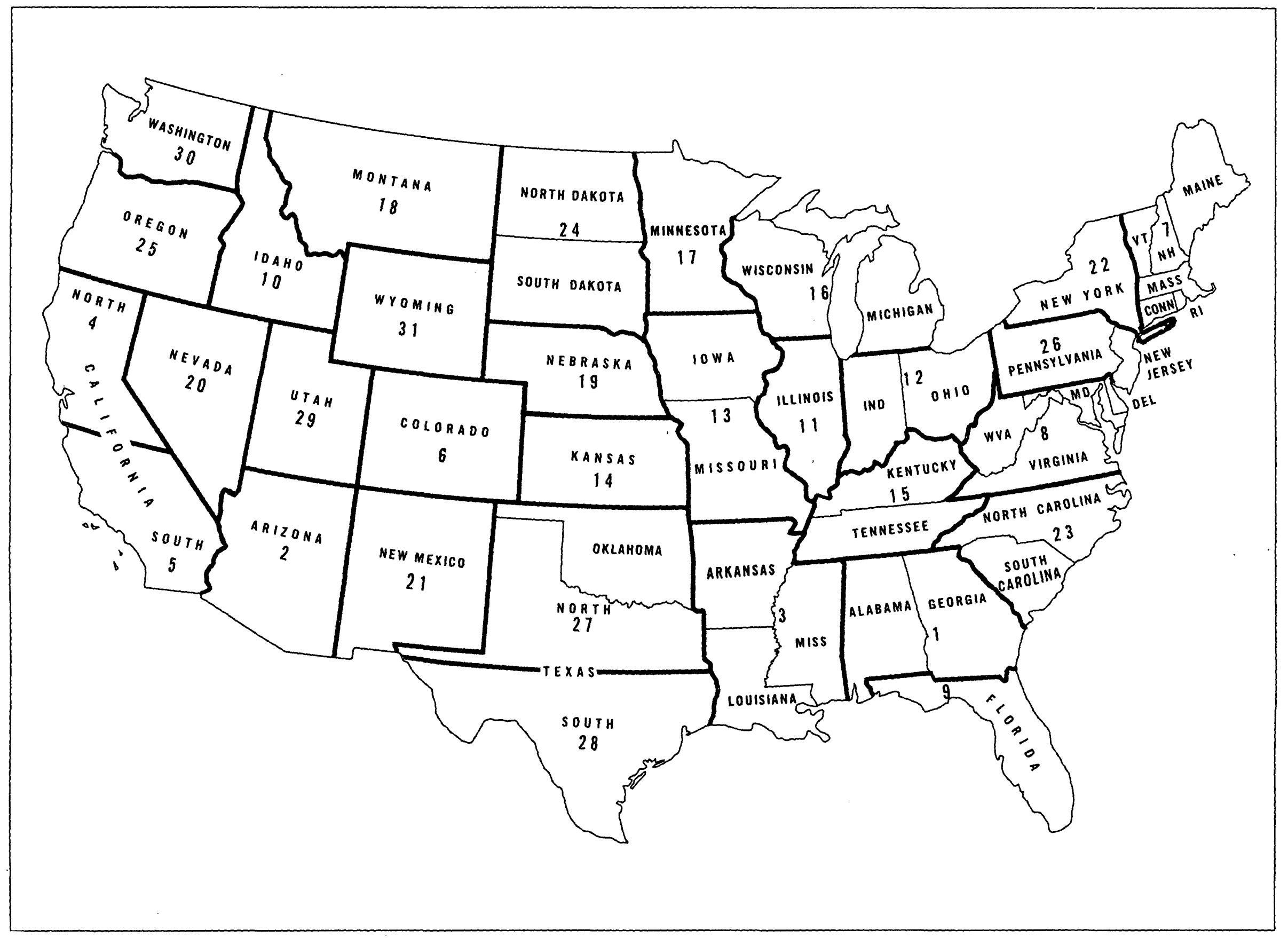


December 1980

APSRS STATE-BASE GRAPHICS

31/ Wyoming

National Cartographic Information Center

National Mapping Division

U.S. Department of the Interior/Geological Survey 

Aerial Photography Summary Record System

State-Base Graphics ............ iv

\section{The graphics}

Planned Projects ...........

Photography flown August 1977 to present 1:40,000 and larger scale ..........

Photography flown August 1977 to present

$1: 40,001$ to $1: 75,000$ scale ........ 3

Photography flown August 1977 to present $1: 75,001$ to $1: 150,000$ scale ........

Photography flown January 1970 to July 1977

$1: 40,000$ and larger scale .........

Photography flown-January 1970 to July 1977

$1: 40,001$ to $1: 75,000$ scale....... .66

Photography flown January 1970 to July 1977

$1: 75,001$ to $1: 150,000$ scale ........

Photography flown 1960 to 1969

1:40,000 and larger scale ......... 8

Photography flown 1960 to 1969

$1: 40,001$ to $1: 75,000$ scale ........ 9

Photography flown 1960 to 1969

$1: 75,001$ to $1: 150,000$ scale ........ 10

Photography flown 1950 to 1959

$1: 40,000$ and larger scale ......... 11
Photography flown 1950 to 1959

$1: 40,001$ to $1: 75,000$ scale ...... 12

Photography flown 1950 to 1959

$1: 75,001$ to $1: 150,000$ scale. . . . . 13

Photography flown 1949 and prior

1:40,000 and larger scale....... 14

Photography flown 1949 and prior

$1: 40,001$ to $1: 75,000$ scale ...... 15

Photography flown by Agricultural

Stabilization and Conservation Service . - 16

Photography flown by Bureau of Land

Management ......... 17

Photography flown by U.S. Forest Service - 18

Photography flown by U.S. Geological

Survey . . . . . . . . . 19

Photography flown by National Aeronautics and Space Administration . . . . . 20

Photography flown by National Ocean Survey 21

Photography flown by Soil Conservation

service. . . . . . . . . 22

Number of Times a 7.5-Minute Quad has been Covered by Aerial Photography. . . . . 23 
The National Cartographic Information Center (NCIC) is the information branch of the U.S. Geological Survey's National Mapping Division. In order to organize and distribute information about U.S. aerial photography coverage and to help eliminate aerial mapping duplication by tracking individual aerial projects, NCIC developed the Aerial Photography Summary Record System (APSRS). APSRS's principal products are StateBase Graphics (SBG), graphic indexes that show the coverage of conventional aerial photography projects over each State.

The graphics are grouped by State location into 34 catalogs. Each catalog contains 23 graphics that show aerial coverage by date of flight and by scale range or agency.

\section{USING THE GRAPHICS}

Except for Alaska, State-base graphics use two reference systems: county boundaries and a grid of latitude-longitude lines. Each sixteenth of a grid area represents a 7.5-minute portion of the Earth and contains either a single character code, a two-character code, or is left blank if there is no information in the data base for a particular scale or time range. Alaska does not have counties. Major rivers are shown as a reference system and the grid lines cover one degree areas.

Codes are explained in an identification block in a corner of each graphic. A single character code identifies the agency that holds the most recently flown aerial photographs for each area within a specific scale and time range. For example, 'A' stands for ASCS, ' 5 ' for NASA.

For a few agencies with nationwide holdings, NCIC produces graphics with two characters in each 7.5minute area which indicate both the scale range and the date of the agency's most recent aerial project. The scale character is coded ' $L$ ', ' $M$ ', or ' $S$ ' (large, medium, or small). The date character is either a number or a letter which indicates the project date. A number between ' 0 ' and ' 9 ' indicates the year of coverage between 1980 and 1989, for example, an '0' means photographs flown in 1980 are available. Projects flown more than 10 years ago are coded by a letter which indicates the decade of coverage. For example, 'E' is the code letter for the 1960's.

\section{ORDERING OTHER STATE-BASE GRAPHICS CATALOGS AND} PRODUCTS

Each catalog is published twice a year. In addition, microfiched listings with more detailed coverage information for each SBG area are published by NCIC. These areas are numbered on the map inside the front cover of each catalog. The catalogs and microfiche listings can be ordered by contacting NCIC's headquarters office at the U.S. Geological Survey, 507 National Center, Reston, VA 22092. Telephone 703-860-6045; FTS 928-6045. 
PLANNED PROJECTS GG GGGGGGGG GGGGGGGGGGGGGGGGGGGGGGGGGGGGGG GGGGGG GGGGGGGGGGIGG GGGGGGGGGGIGG GWGGGGGG GG GG G $\&$ G G GG G G GG GG GGIGG GG GG GGGG GGGG GG GG GGGG GG: GG GGGG-GGGE-GG GGGGIGG GGGG GGGG GGGG G G-GG-GGGG-GS GGGGGG GGIGG GG GG GGIGG GG GG GGIGG GGGG GG GG GGIGG G W

44

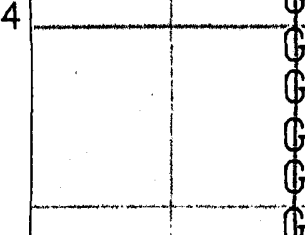

GG GGGGGGIGGGGGG GGGG GGGG GGGGGGGGGGGG GGGGGG

GG GG GG GGG G G G GG GGIGG GG GG GGGG GGIGG GG:GG GG:GG GG

GG GGGG GGGGGGGG GGGG GGGG GGGG GGGG GG'GG GGGG GG: GGGGGGGGGG GGIGG GGGG GGGGGGGGGGGGGGGGGGGGGG GG GGGGGGGGGGGG GGGG GGIGGGGGGGGGGGGGGGGGGGE
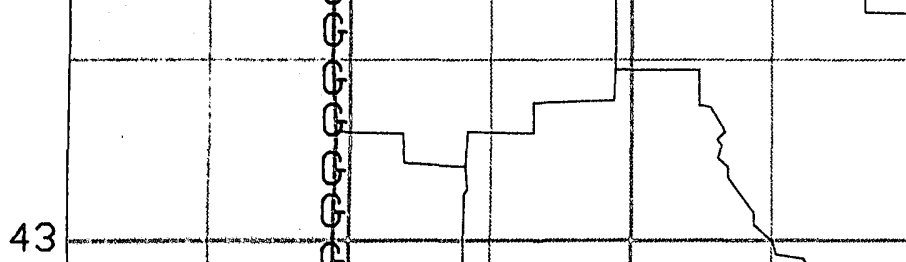

43

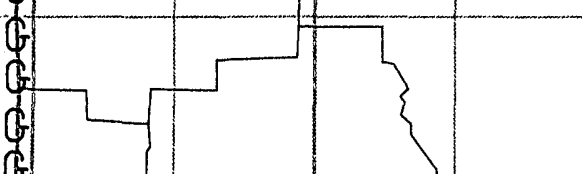

GG GGGG GGGG GGGG GGGG GGGG GGGG GGGG GGOG GGGG GS

GG GGGG GGGG GGIGG GGGG GGGG GGGG GGGG GGGG GGGG GG

GG GGGG GGGG GGJGG GGIGG GGGG GGGG GGIGG GG GG GGGGG GG

41

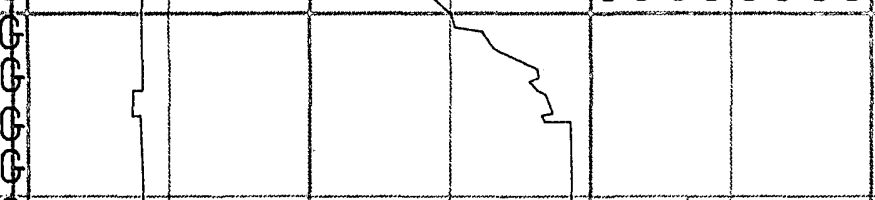

GGGGGGGGGGGGGG GGGG GGGG GGGG GGGGGG GG GGIGGGGG GGGG GG:GG GGGGGGOGGGGGGG GG GGGG GGIGG GGGG GGGG GGGG GG.GGGGGG GG GG GGGG GGIGG GG GG GG;GG GGGGFGGGGGGGGG GG GGGGGGGGGGGGGQGG GGIGG GGGG GGGG GQ: GG GG GG GGIGG GGGG GG GG GGGG GGGG GGGG GG: GGGGIGGGGGG GGGG GG!GG GGIGG GGGGGGGGGG: GG GGGG GGGGGGGG GGIGG GGGGGGIGG GGGG GG 42 GGGGGGGGG G.GGGGGGGG CGGGGGGGG

GTGGGGGGO GGGGGGGGG $\$ G G G G G G G G$ 41 QGGGGGGGG GGGG GG GGIGG GGGG GGGG GGGG GG GG OGGG GG GG GG GG GGIGG GG GG GG GG GGGG GGGG GGIGG GG: GGGGIGG GGGG GGGG GGIGG GGGGGGGGOGIGG GW GG GGGG GGIGG GGGG GGIGG GGGG GGGG OGGGGG: GGGGIGGGGIGG GG GGGGGGGGGG GGGGGGGG GG GG GGGGGGGG GGGGGGGG GGGG GGGG GGGGGG GG GGGG GGGGGGGG GGIGG GGGGGGGGGGIGGG GGGGGG GGIGG GGIG G GGGG GG GG GGGG GGGG GW 
U.S. DEPARTMENT OF THE INTERIOR — GEOLOGICAL SURVEY

AIONAL MAPPING DIVISION

NATIONAL CARTOGRAPHIC INFORMATION CENTER

\section{Wyoming}

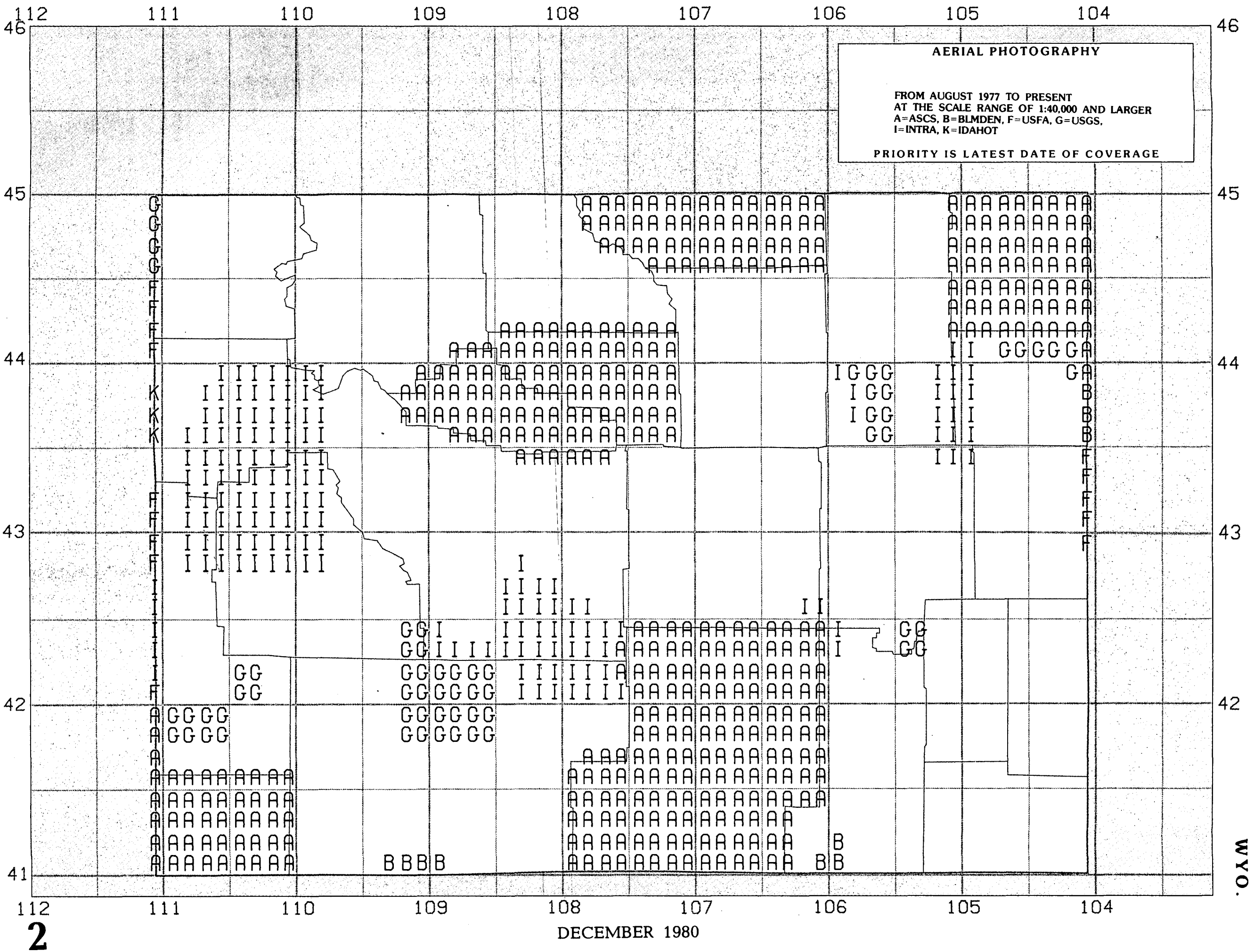


U.S. DEPARTMENT OF THE INTERIOR • GEOLOGICAL SURVEY NATIONAL MAPPING DIVISION

NATIONAL CARTOGRAPHIC INFORMATION CENTER

Wyoming

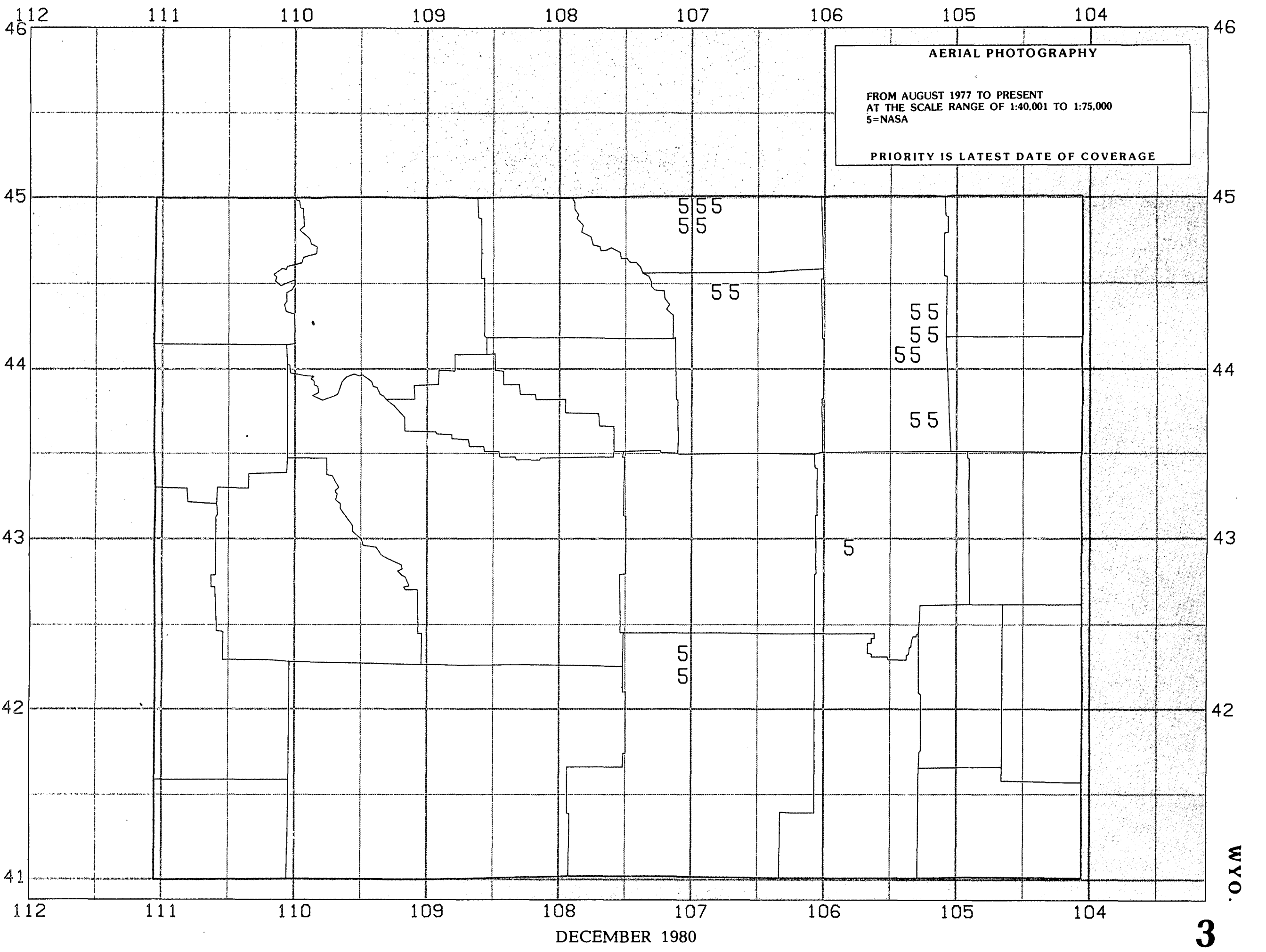




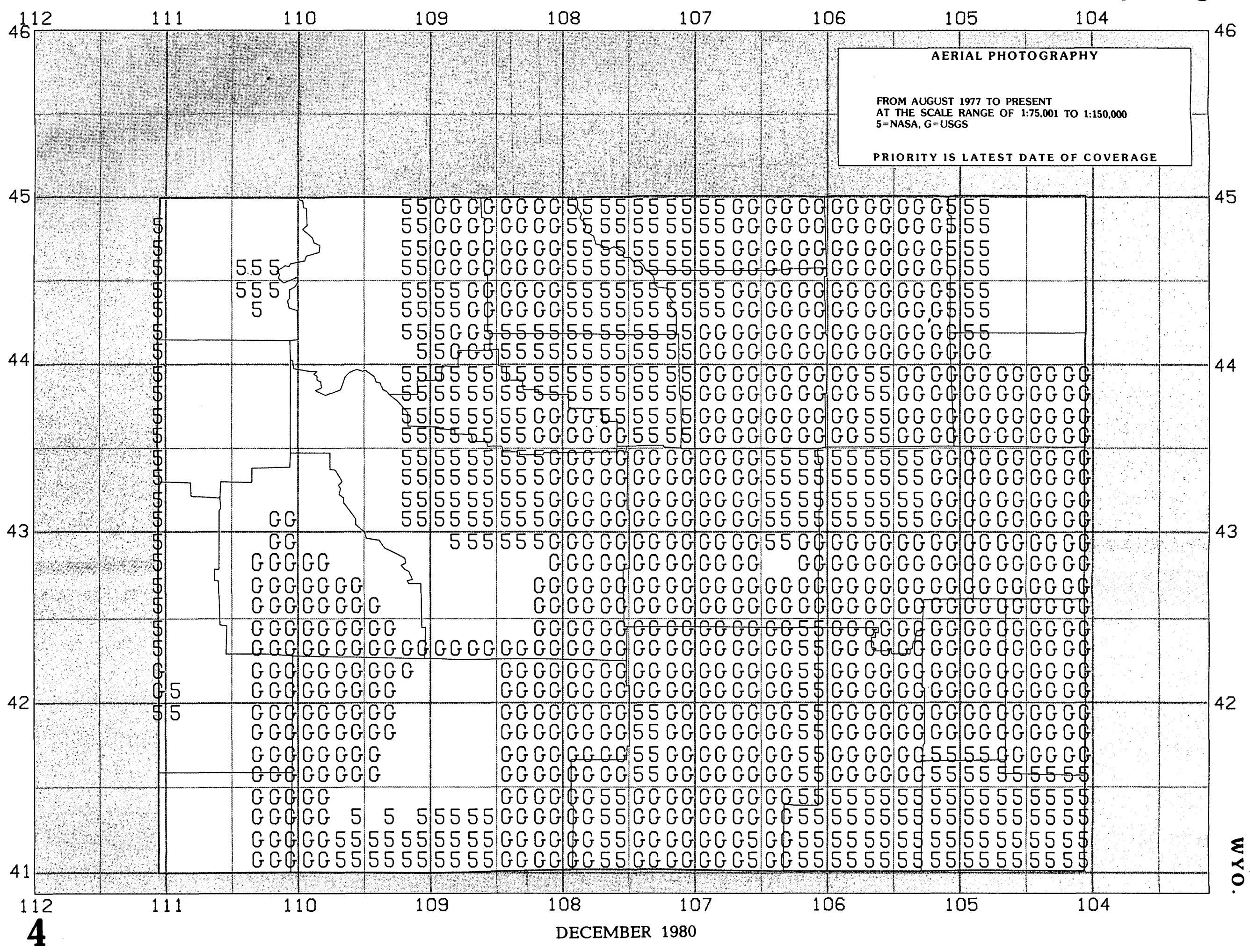


U.S. DEPARTMENT OF THE INTERIOR • GEOLOGICAL SURVEY NATIONAL MAPPING DIVISION

NATIONAL CARTOGRAPHIC INFORMATION CENTER

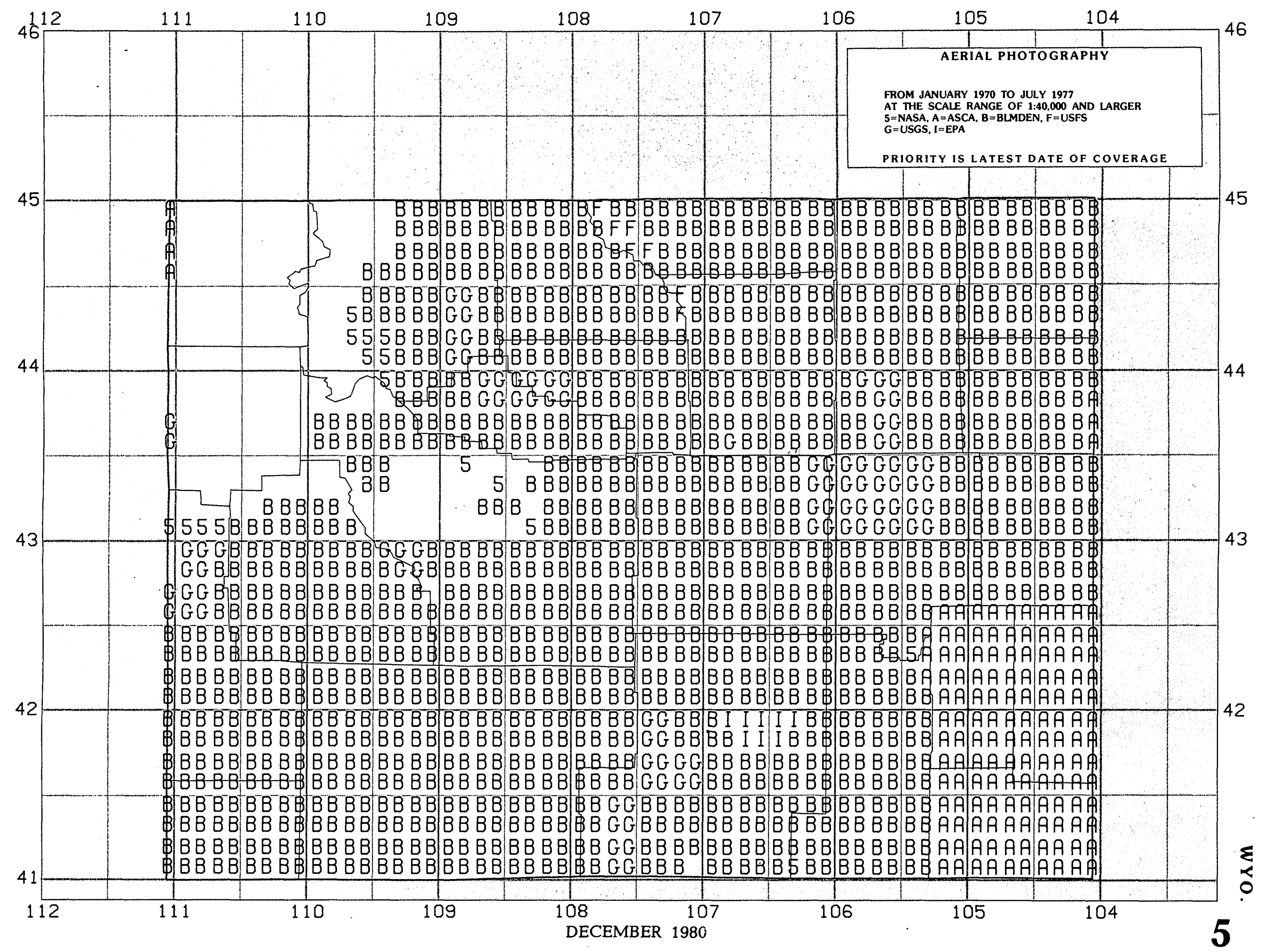


U.S. DEPARTMENT OF THE INTERIOR • GEOLOGICAL SURVEY

NATIONAL MAPPING DIVISION

NATIONAL CARTOGRAPHIC INFORMATION CENTER

Wyoming

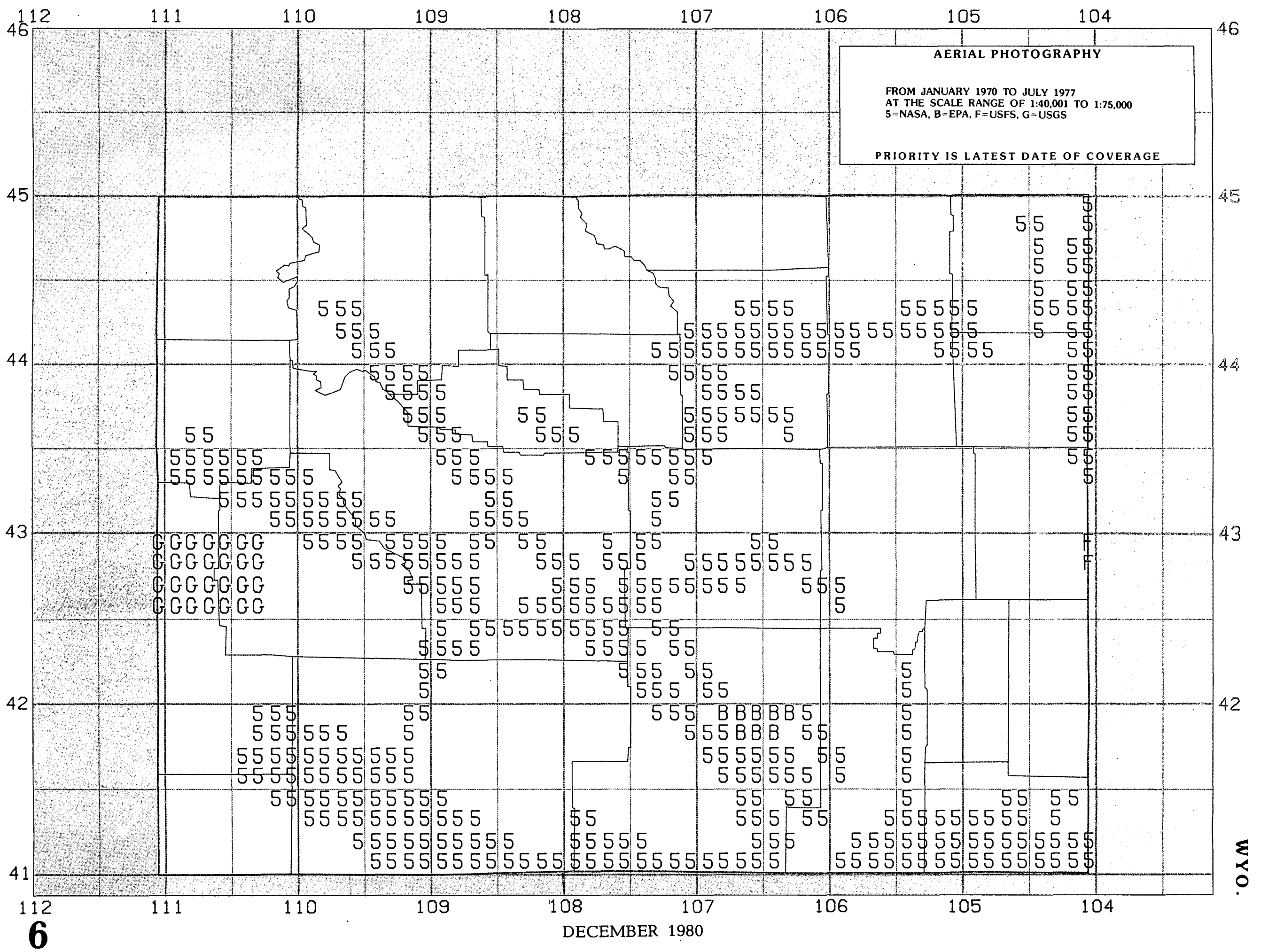


U.S DEPARTMENT OF THE INTERIOR • GEOLOGICAL SURVEY NATIONAL MAPPING DIVISION

NATIONAL CARTOGRAPHIC INFORMATION CENTER

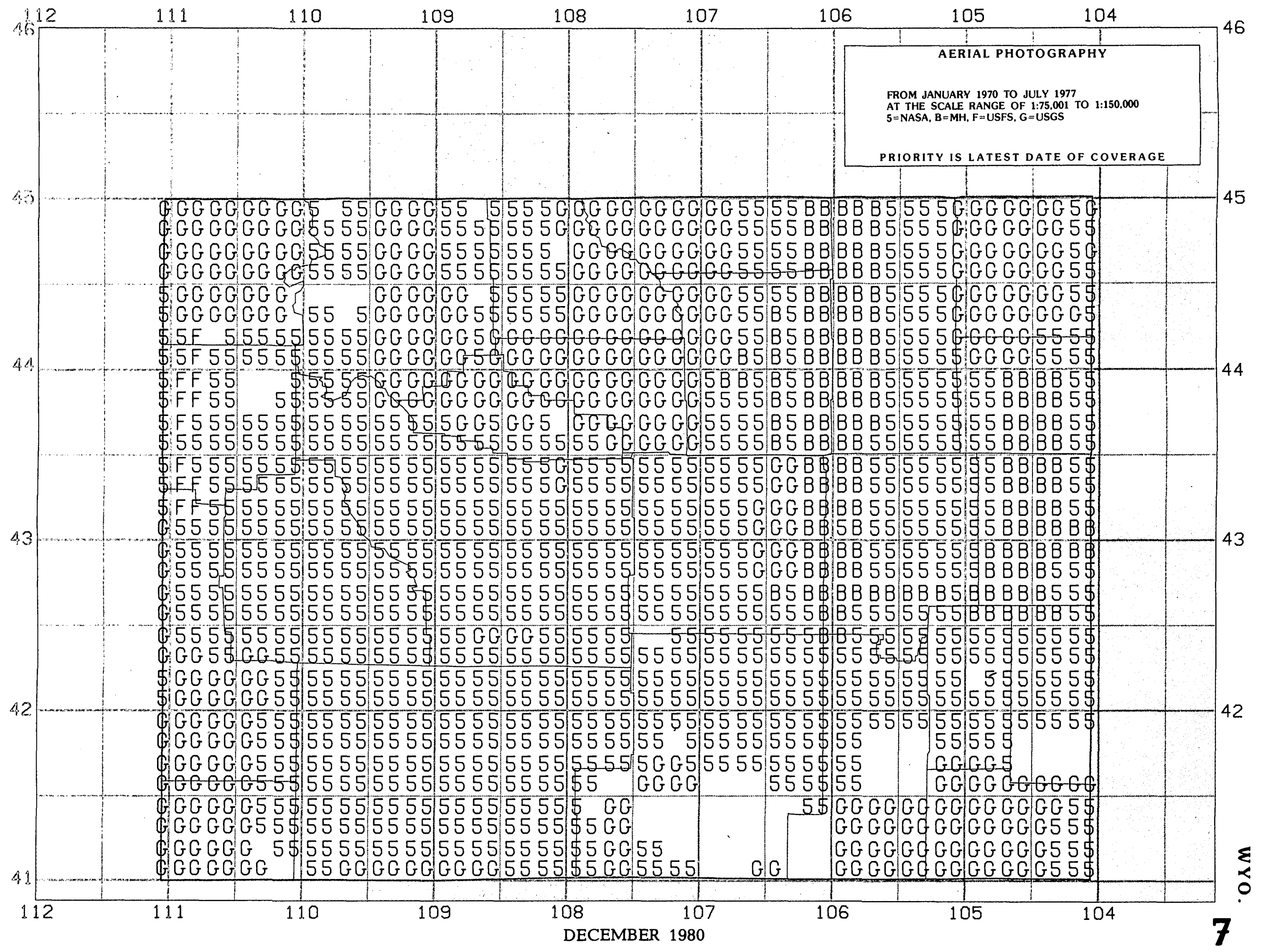




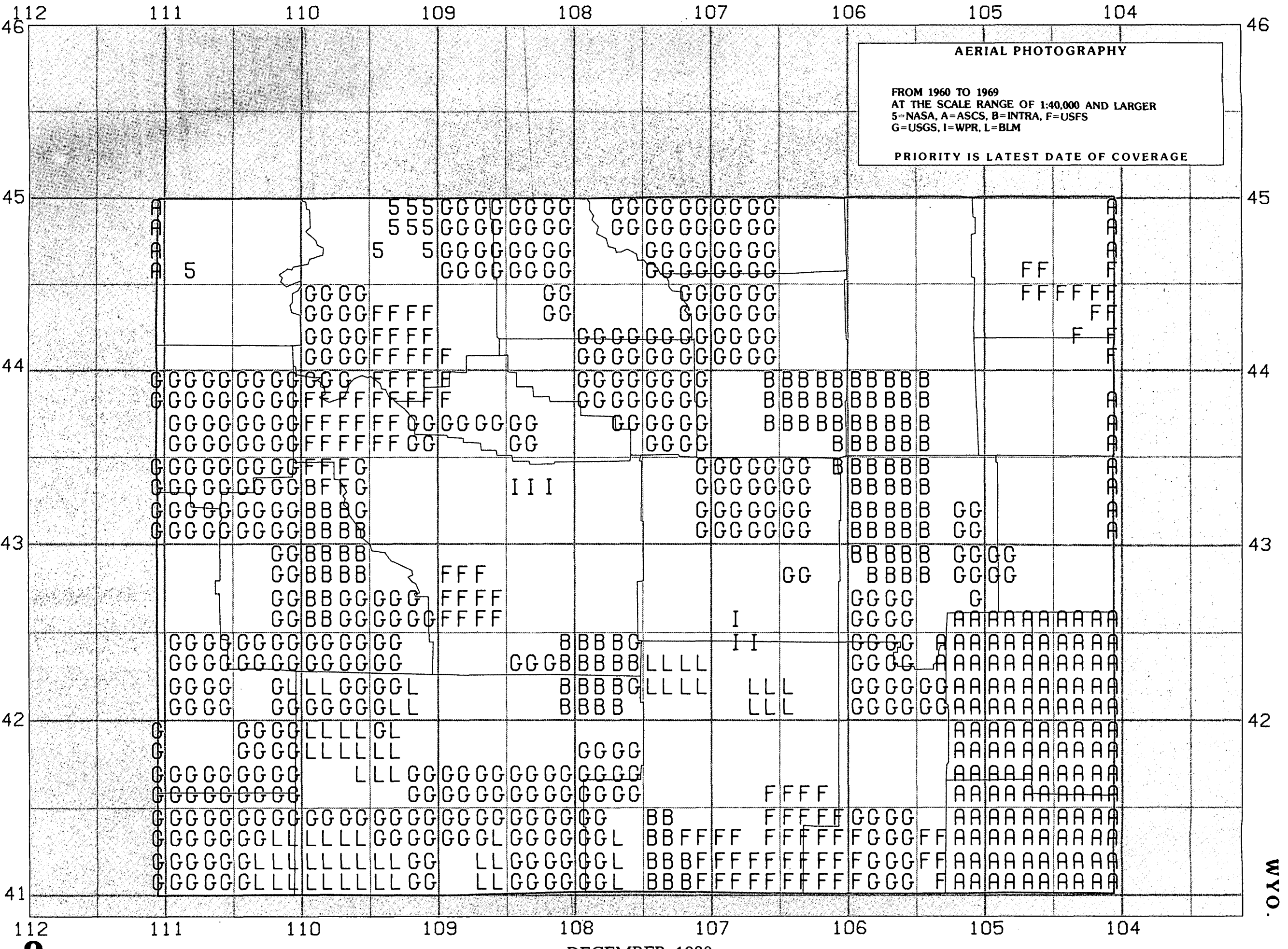


S. DEPARTMENT OF THE INTERIOR • GEOLOGICAL SURVEY

NATIONAL MAPPING DIVISION

NATIONAL CARTOGRAPHIC INFORMATION CENTER

\section{Wyoming}

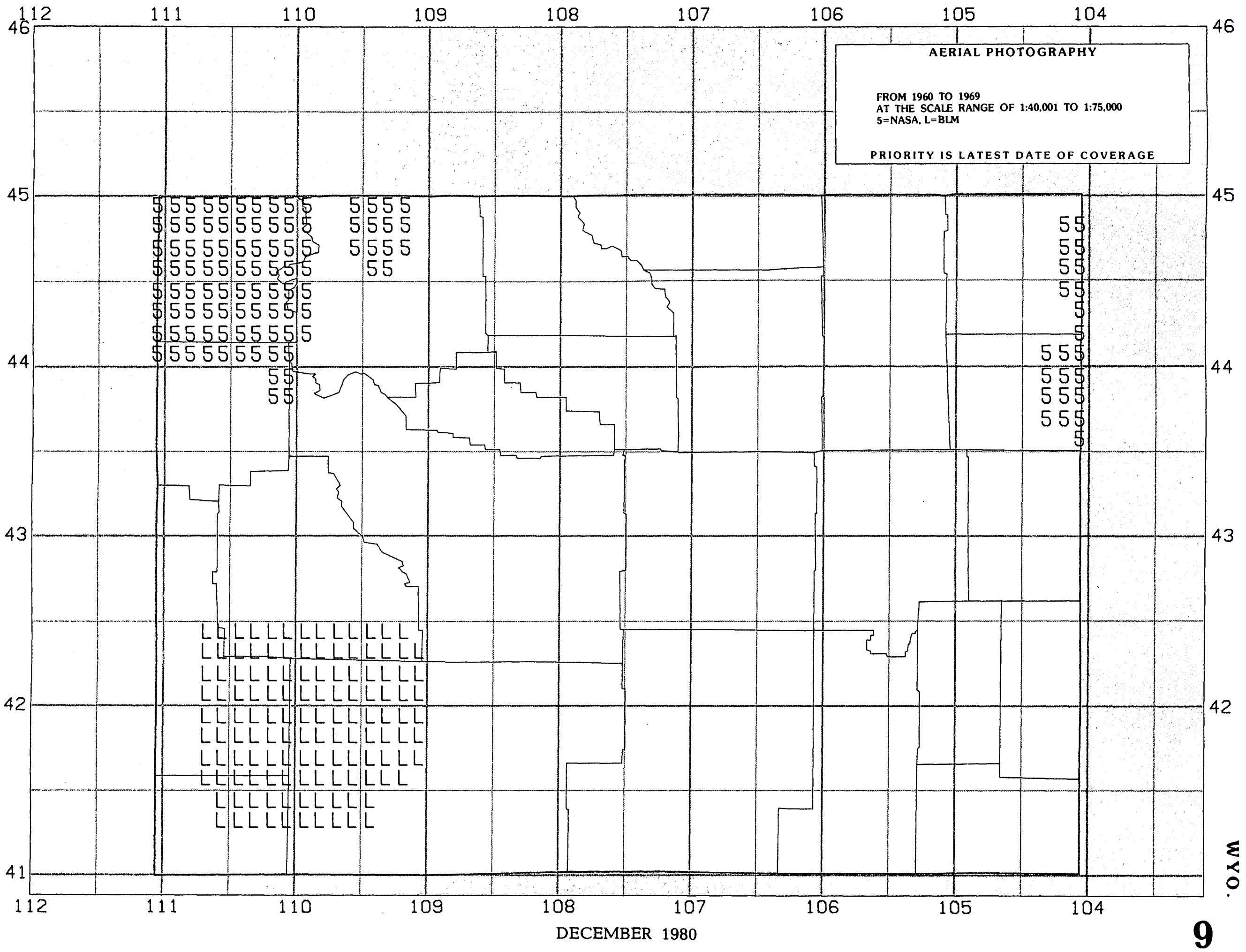


109

108

107

106 105 AERIAL PHOTOGRAPHY

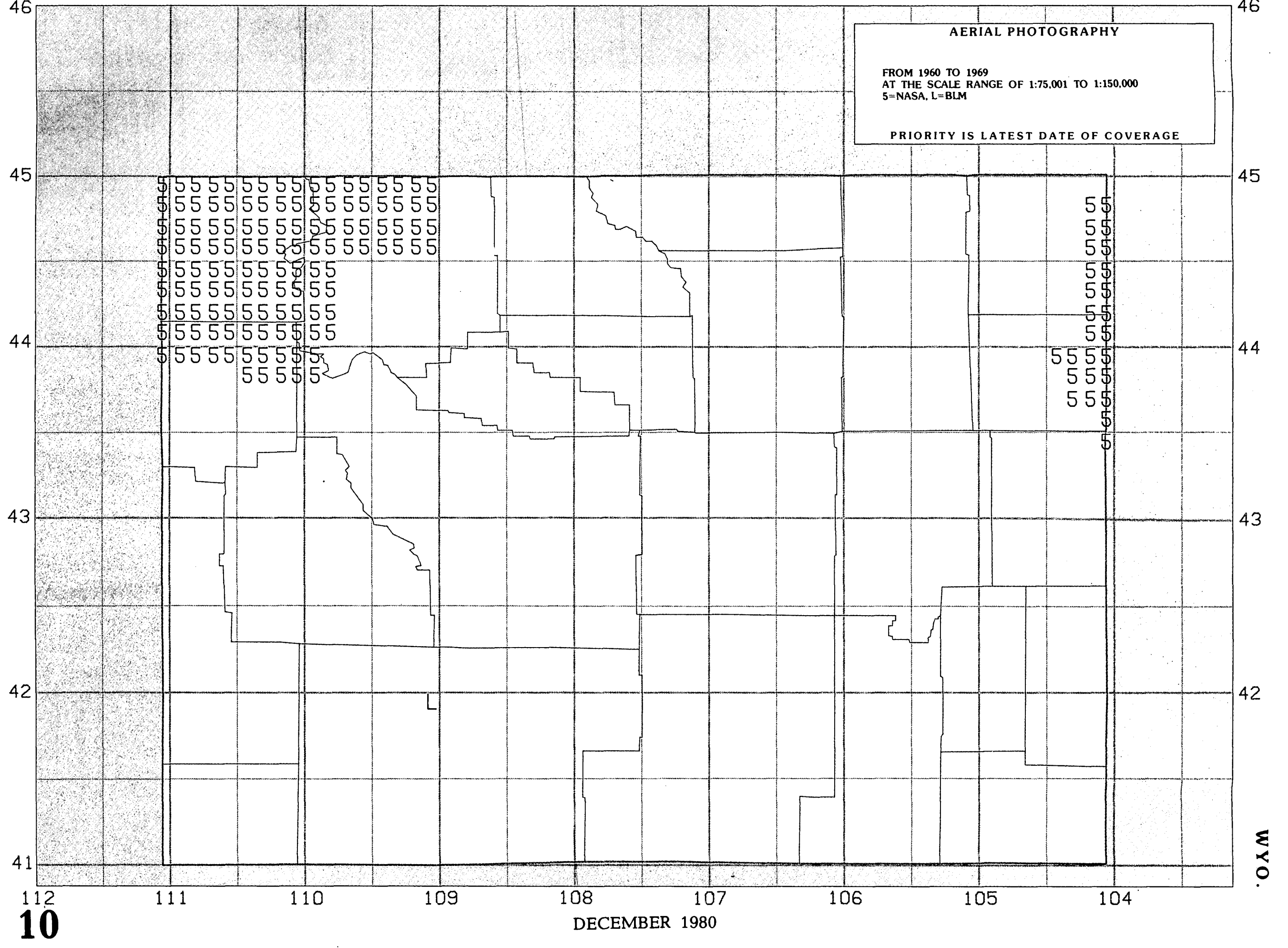


U.S. DEPARTMENT OF THE INTERIOR • GEOLOGICAL SURVEY NATIONAL MAPPING DIVISION

NATIONAL CARTOGRAPHIC INFORMATION CENTER

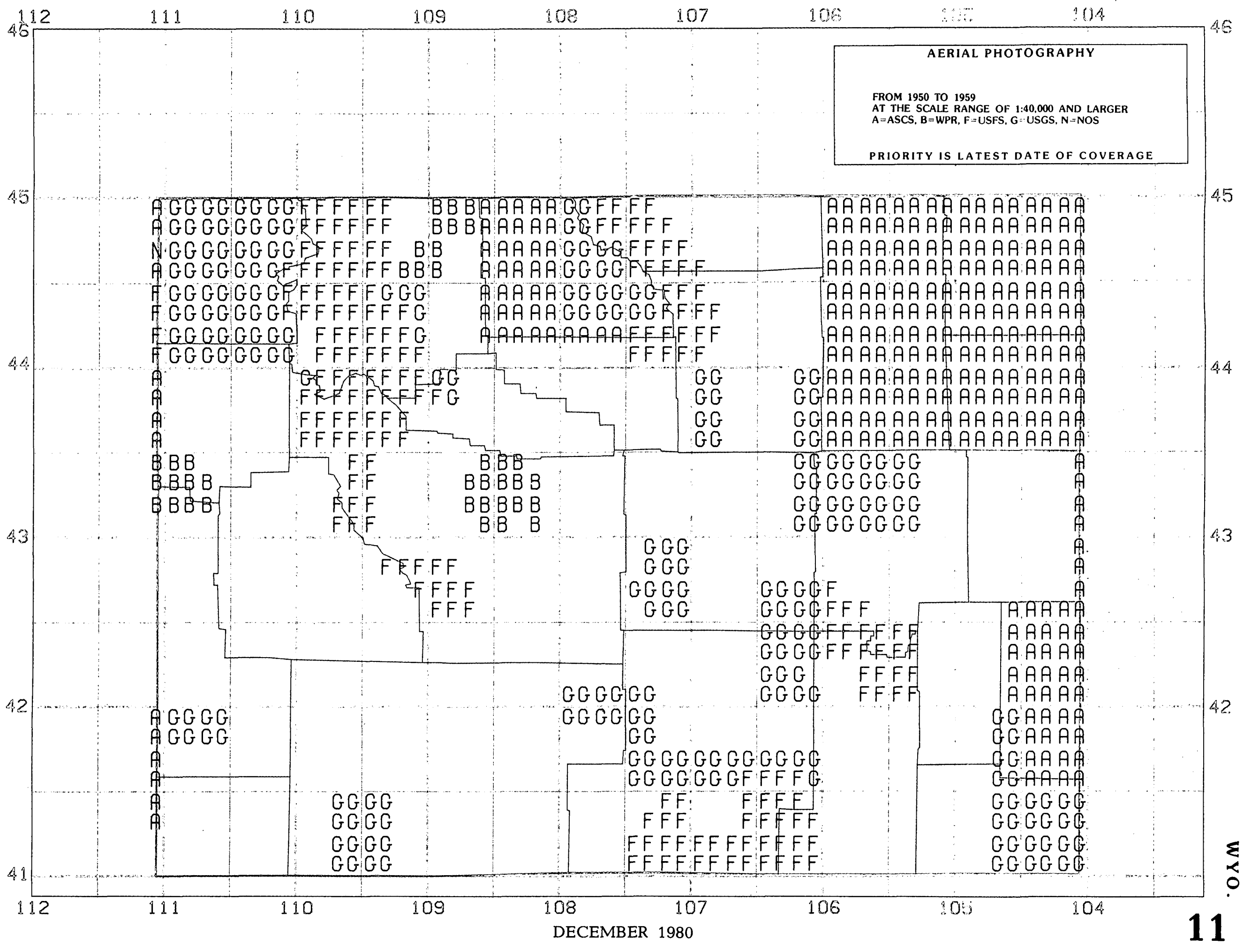




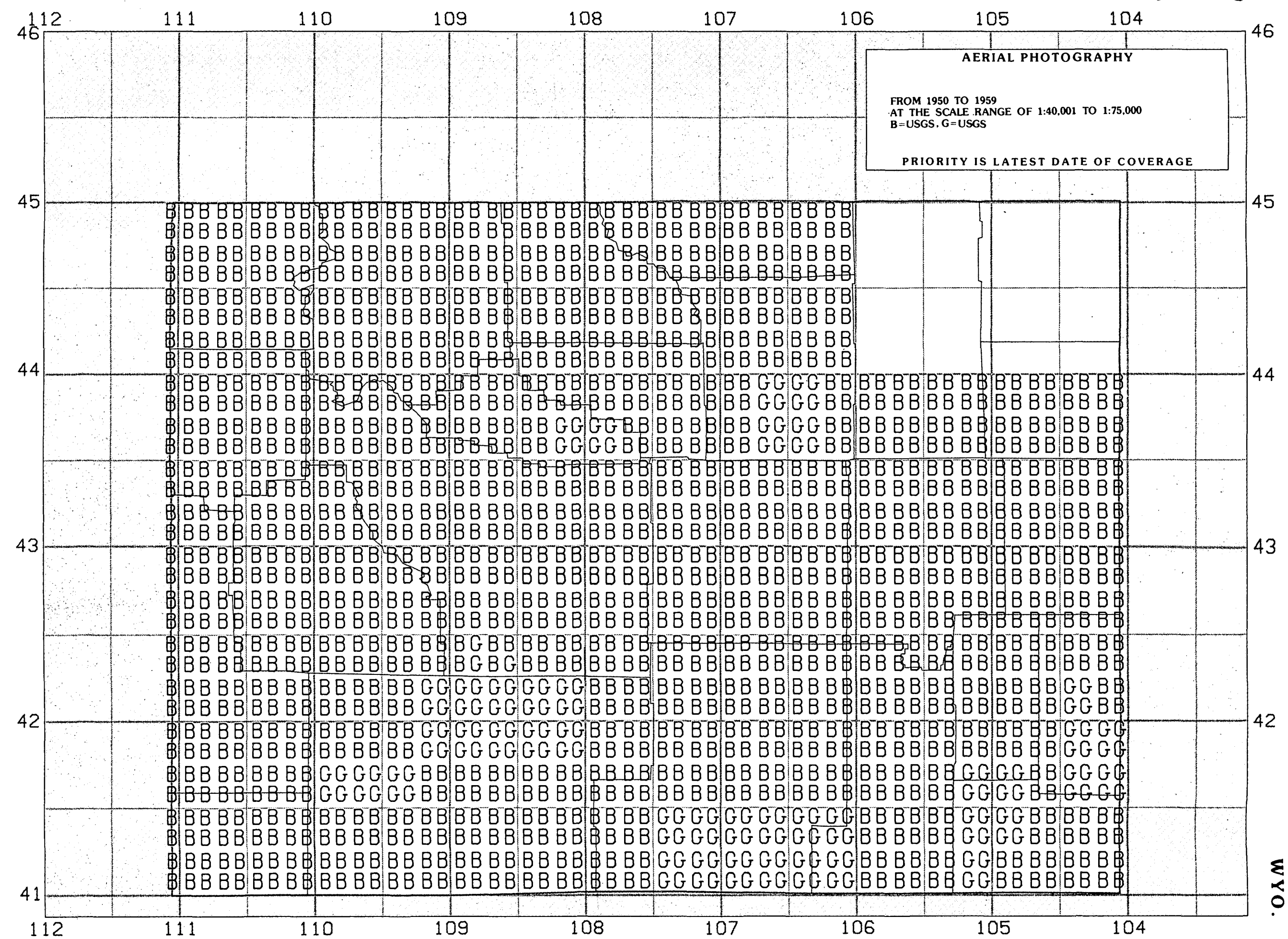

\section{Wyoming}

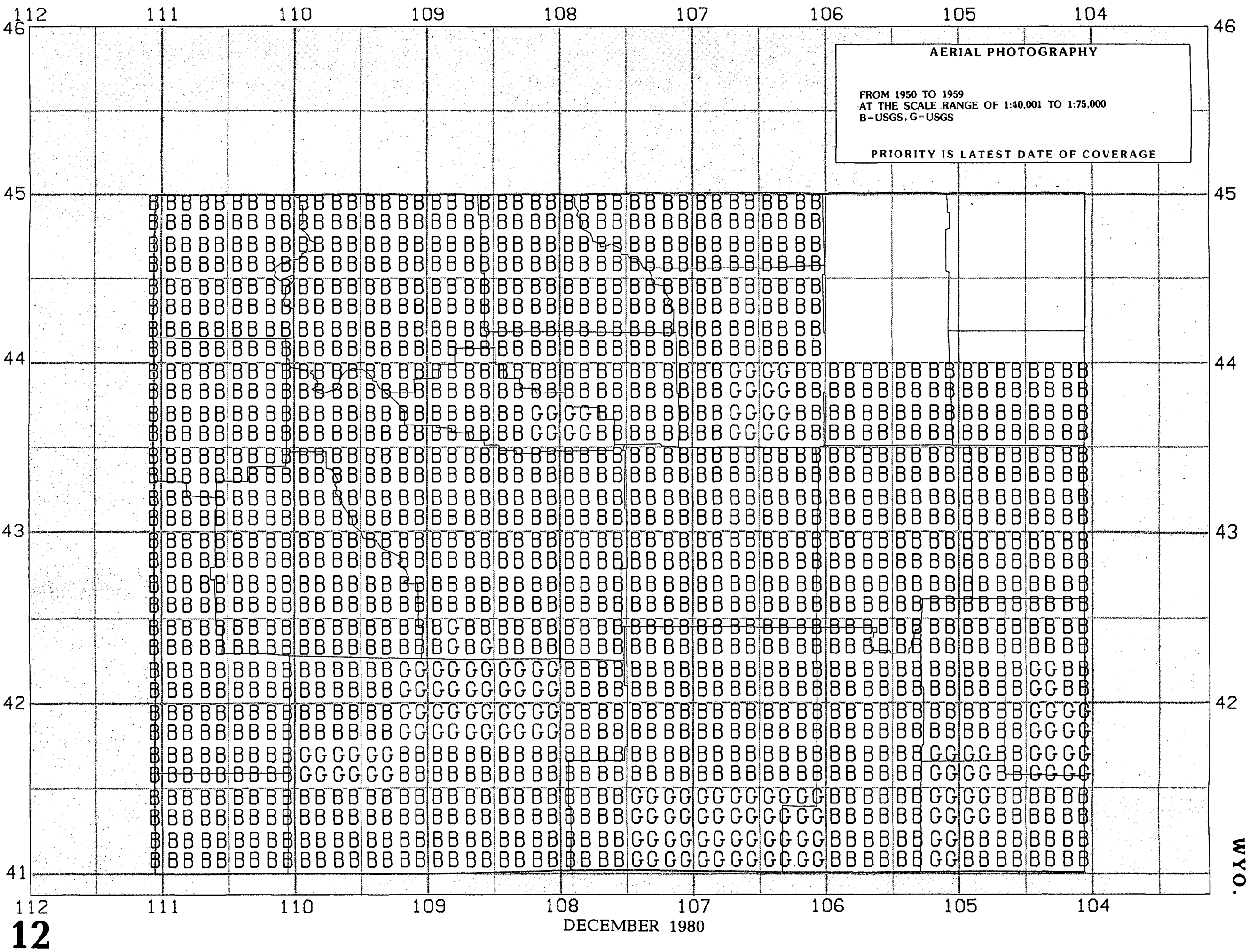


U.S. DEPARTMENT OF THE INTERIOR • GEOLOGICAL SURVEY

NATIONAL MAPPING DIVISION

NATIONAL CARTOGRAPHIC INFORMATION CENTER

Wyoming

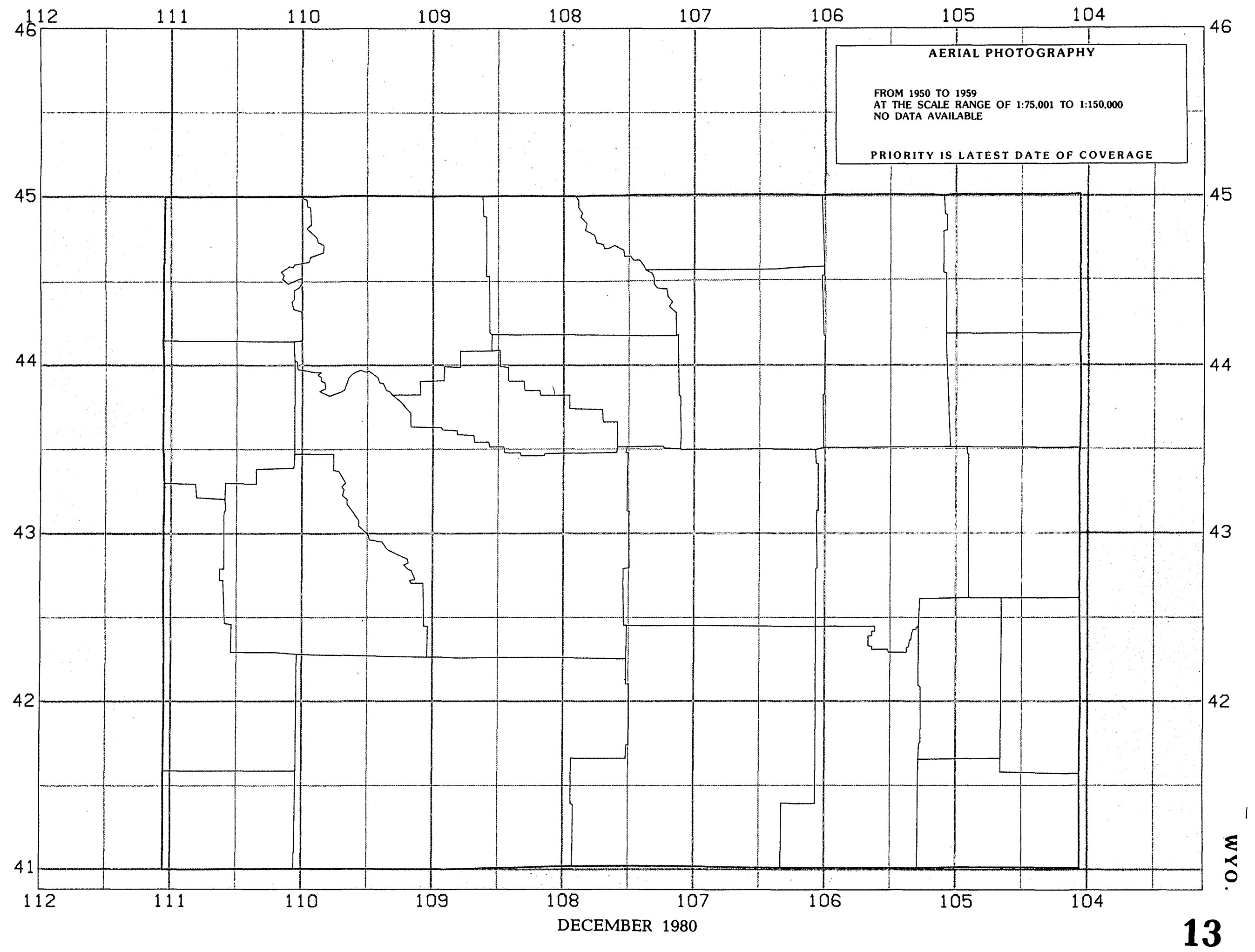




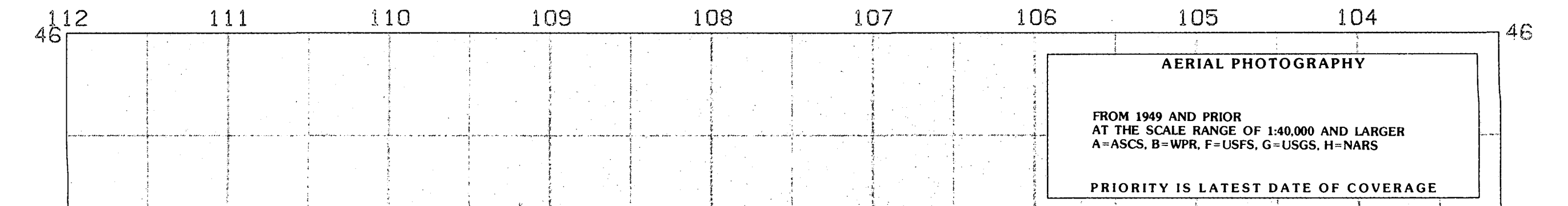

\section{Wyoming}

45. H. H H H H HHHHQG GG GH HHHHHH HB BBHHHHHHHHHHHHHH HHH HH HH HHGG GGGG GGHH HH HB HH HH HH H H H H H H H H HH H HHHHHIHHHGGGGHHHHHB HHHH HHIHHHHHHHHHHH

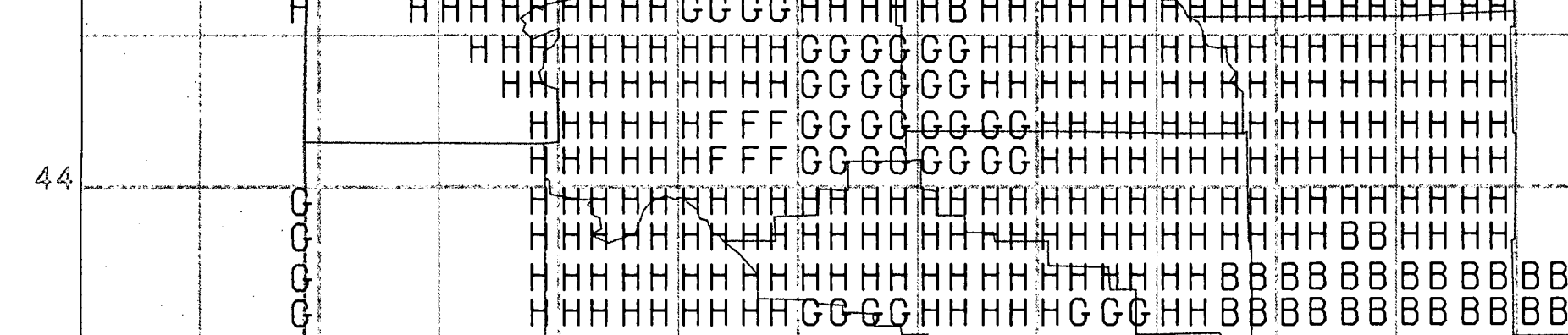
HAHIHHGGGGGG GGGGGGGGGGGGGBBBBBBBBB HH HHHHBHHHHGGGGGGGGGGGGGGGGGGGBBBBBBB B B HHHHH HHHHHHHGGHHHHGGGGGGGGGGGGGBBBBBBBBB: 43 HHHHHBBBHHHHGGHHHGGGGGGGGGGGGGBBBBBBBBB HHH HHBBB HHHHH HHGGGGGGGGGGGGGBBBBBGGGG GGGGGGGG HHHHHHB BBBB BBHHWHHH GGGGGGGGGGGBBBBB GGGGGGGGGGGG HHH HHHB BB:BBBBHHHHHGGGGGGGGGG GGGGGGGGGGGGGGGGGG HHHHHHB BBBBBBHHHHHHGGGGGGGGHH GGGGGGGGGGGGGGAAPAARAARA HHHHHHB BB BB BB HHHHGGGGGGGGGGGGGGGGGGGGGGGGGG GGGA AAAAAAAAAA HHH HHHB BB:BB BBHHHHHH HHHH HHHH HHHH GGGGGGGGGGGGGGGA AAAAAAAA AA HHH HBGBB!BB BBHH HGGHHHHHHHHHHHHGGGGGGGGGGGGGGGAGGGGAAAAAA HHHB GGBB:BB BB:H HGGHHHHHHHHHHH GGGGGGGGGGGGGGGGGGGGAAAAAA H H H B B B B B B B H H H H HHHHHHHHHHHHGGGGGGGGGGGGGGGGGGGGAAAAAA

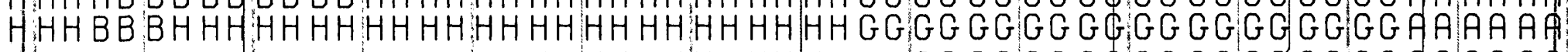
GHB BB B B HHH HHHH HHHHHHH HHHHHHHH HHGG GGGGGGGGGGGGAABAAAAA AA GHB BB:BB BHHHHHH HHHH HHHH HHHHHHHHHHGG GGGGGGGGGGGGAAIAAAAAAAA H HB BB B B B HHHHHHHHHHHHHHHHHHHH HHGG GGGGGGGGGGGGAAIAAAAAA A H HB BB BB BHHHHHHH HHHHHHHHHHHHHHHH HHGGGGGGGGGGGGGGAAIAAAAA A HHB BB BB BHHHHHHHHHHHHHH HHHHHHHHHHHHHGGGGGGGGGGAAAAAAAAAA 41 HHB BBBB BHHH HHHHHHHHHHHHHHHHHHHHHHHHHGGGGGGGGGGAAAAAAAAAA

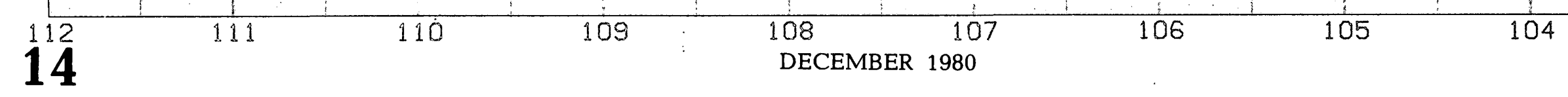




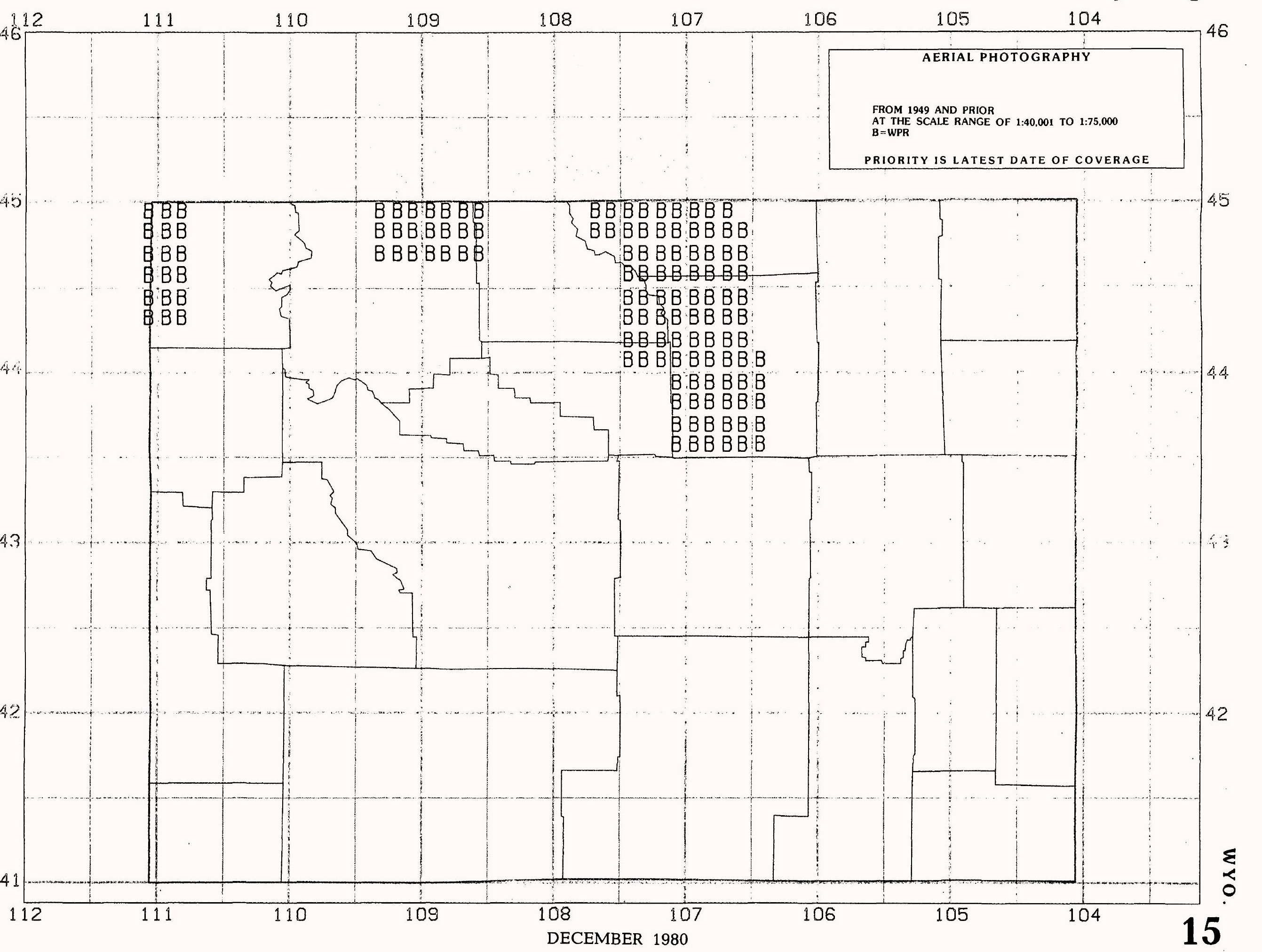




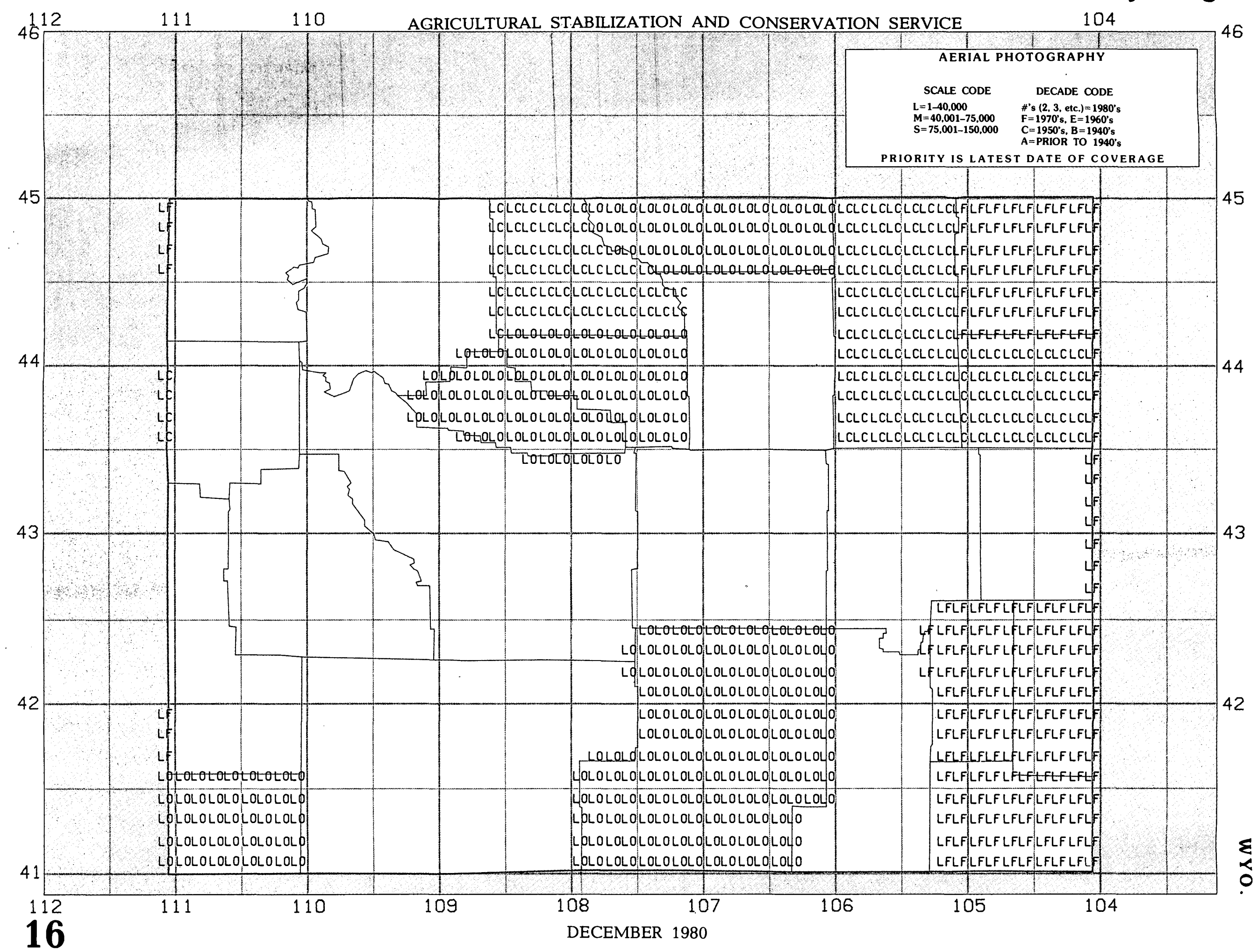

Wyoming

\section{AERIAL PHOTOGRAPHY}

SCALE CODE
$L=1-40,000$
$M=40,001-75,000$
$S=75,001-150,000$

PRIORITY IS LATEST DATE OF COVERAGE 
U.S. DEPARTMENT OF THE INTERIOR • GEOLOGICAL SURVEY

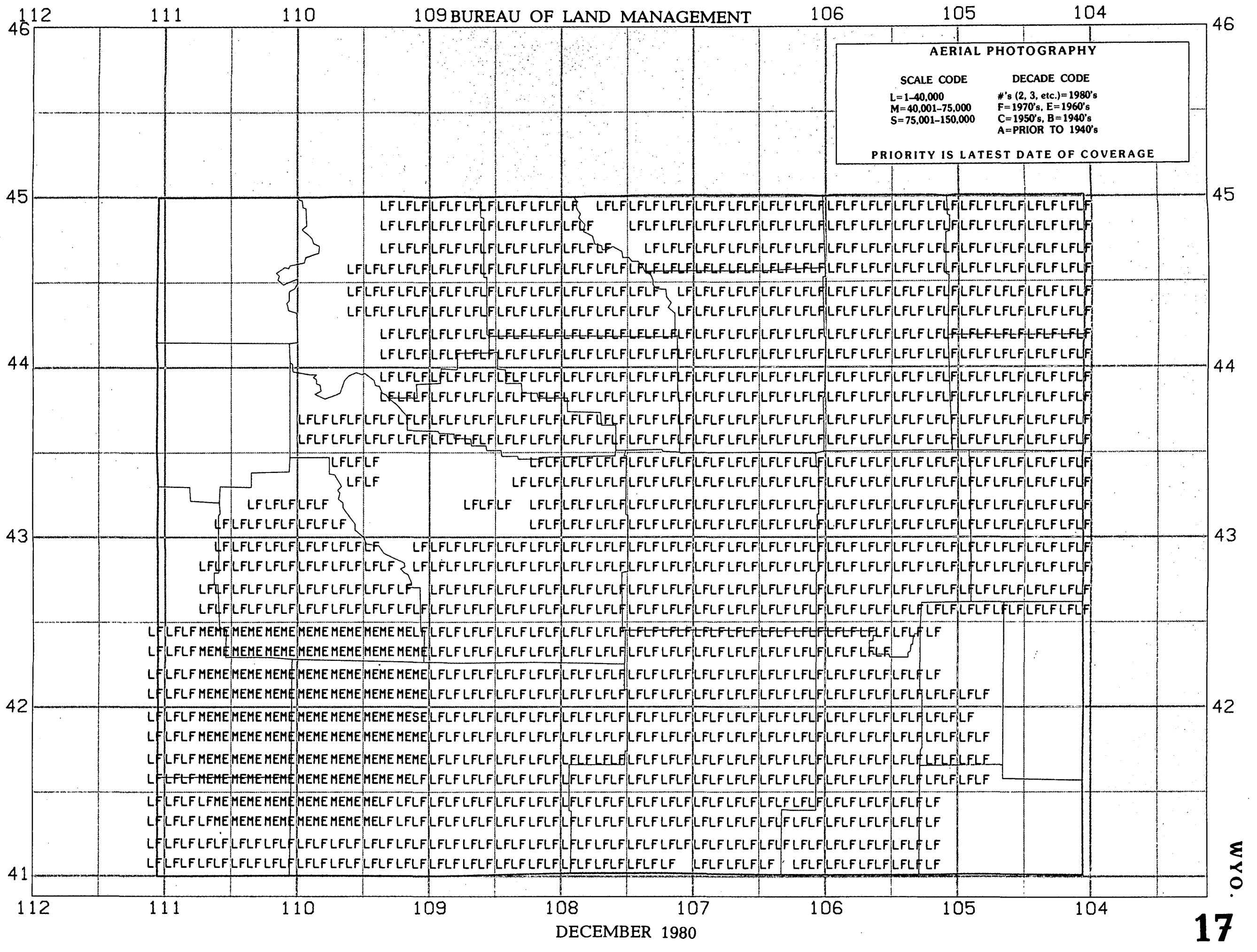




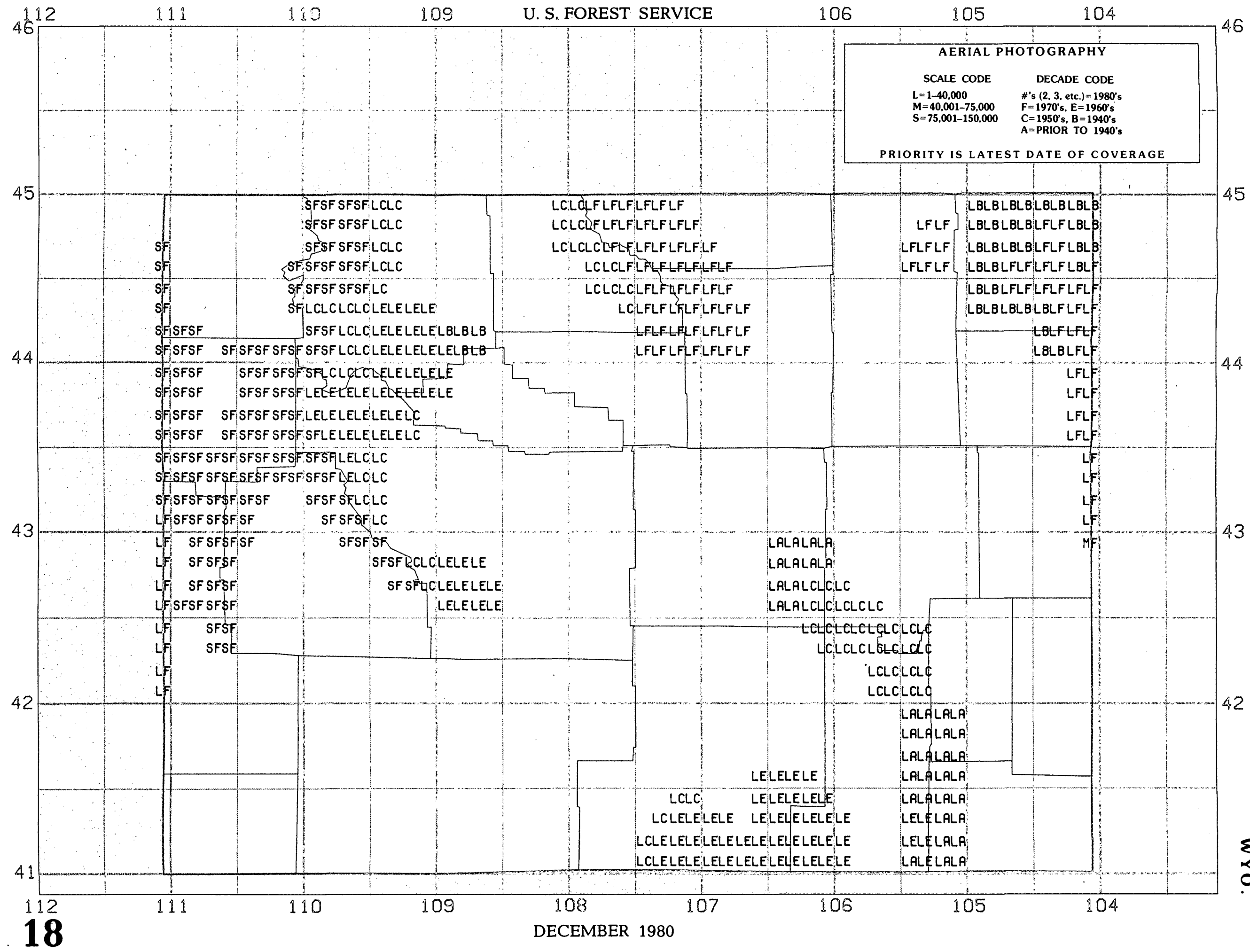




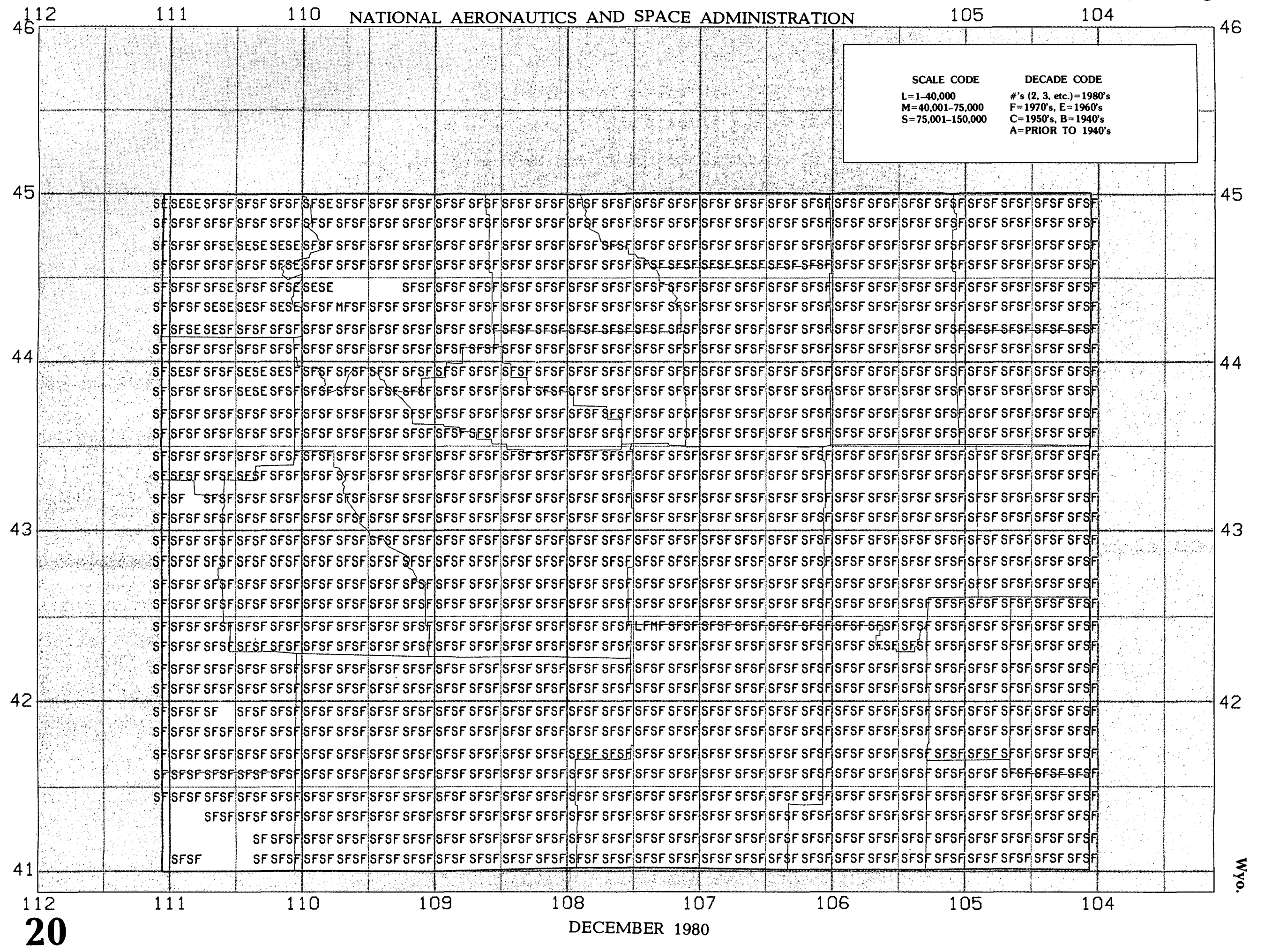


U.S. DEPARTMENT OF THE INTERIOR • GEOLOGICAL SURVEY NATIONAL MAPPING DIVISION

NATIONAL CARTOGRAPHIC INFORMATION CENTER

Wyoming

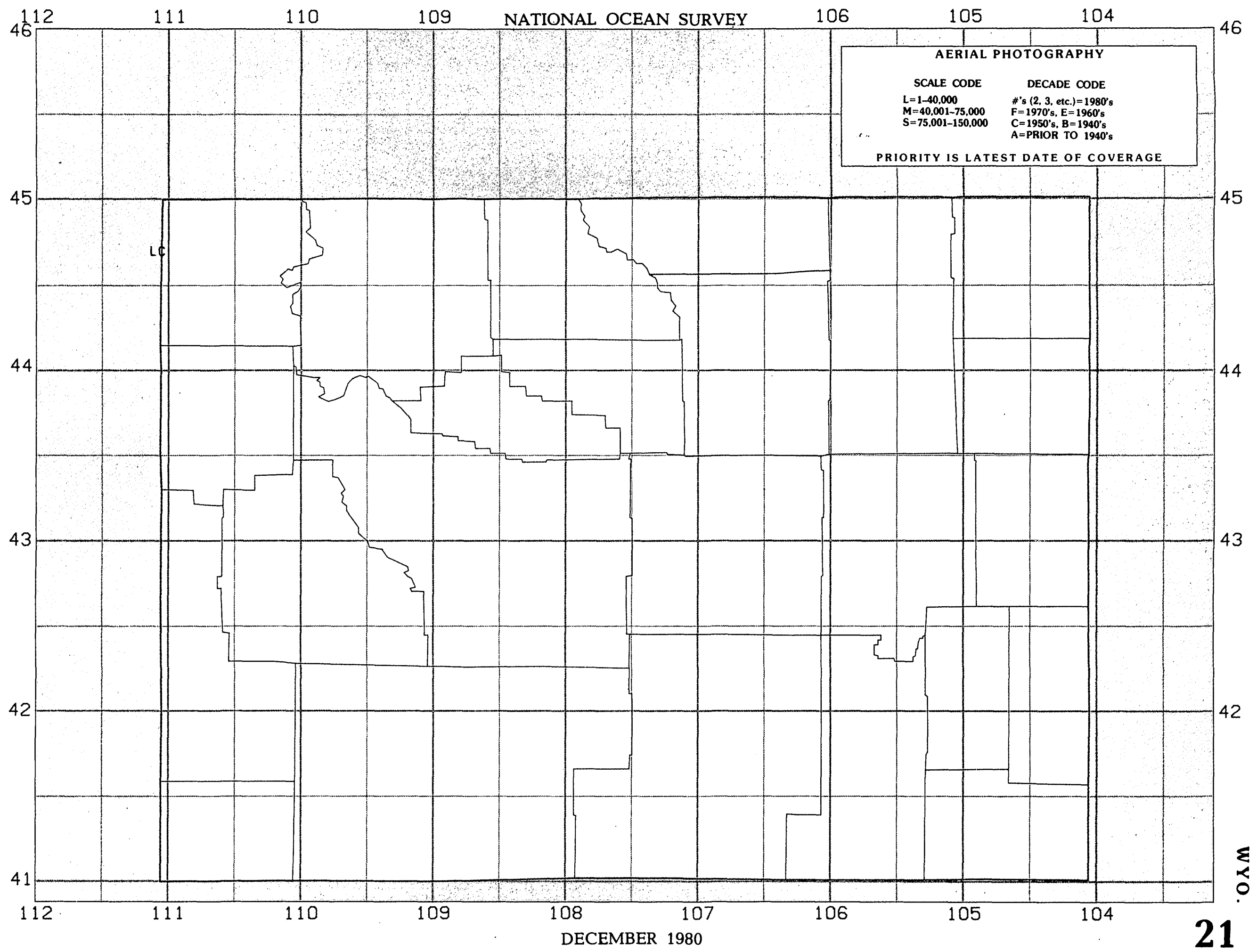


U.S. DEPARTMENT OF THE INTERIOR $\bullet$ GEOLOGICAL SURVEY

NATIONAL MAPPING DIVISION

Wyoming

NATIONAL CARTOGRAPHIC INFORMATION CENTER

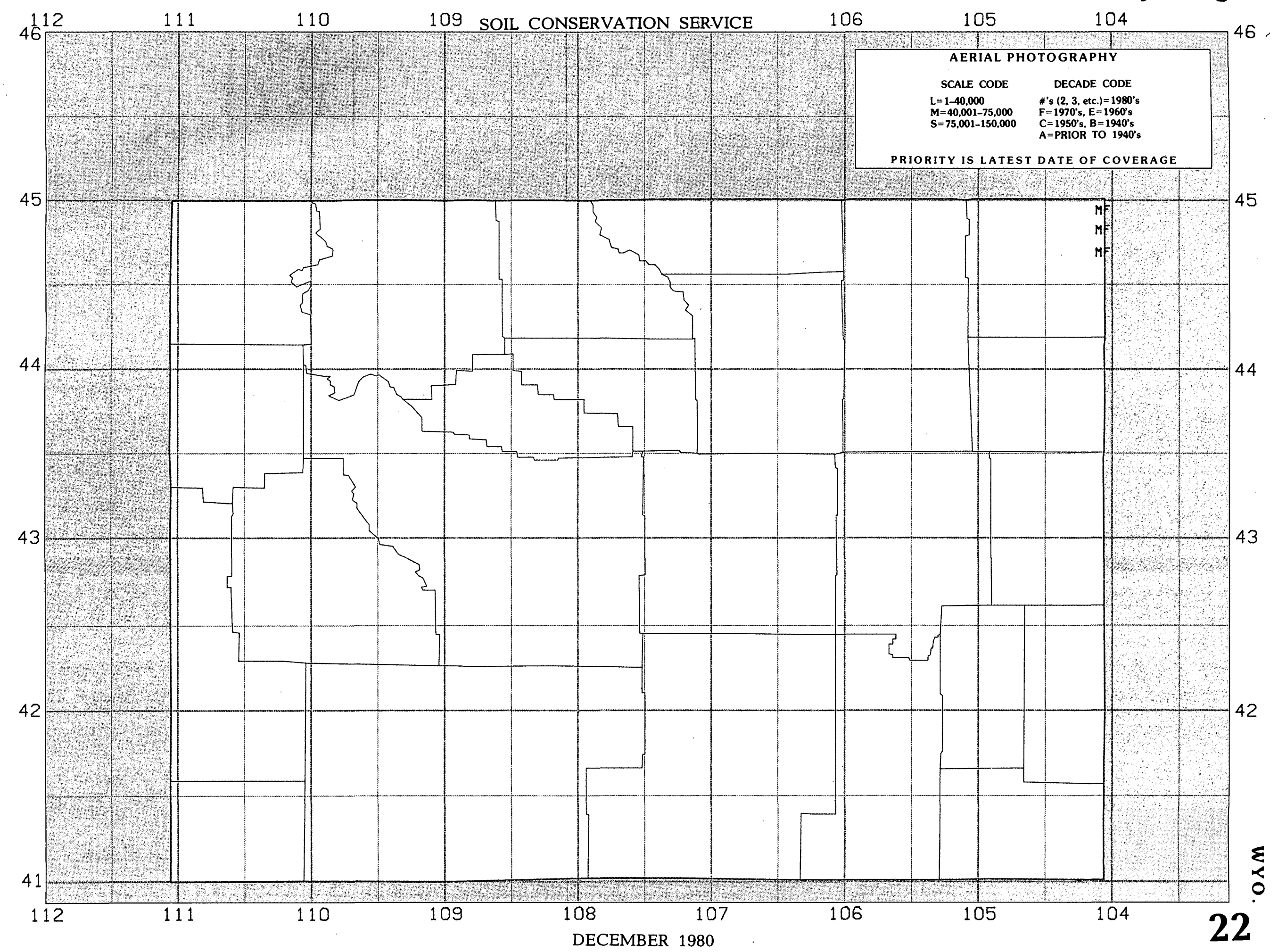


U.S. DEPARTMENT OF THE INTERIOR • GEOLOGICAL SURVEY

NATIONAL MAPPING DIVISION

NATIONAL CARTOGRAPHIC INFORMATION CENTER

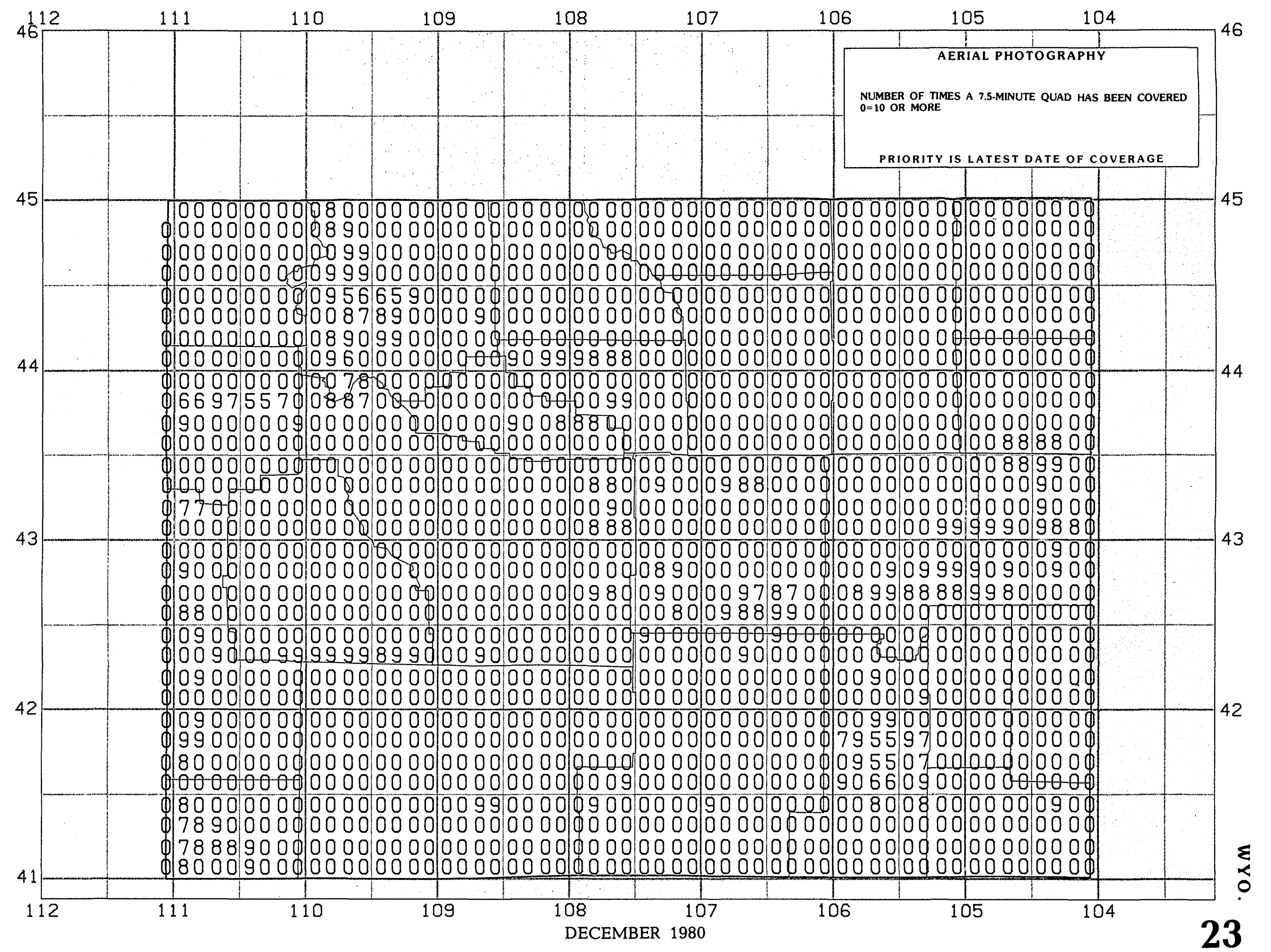

